\title{
Column Experiment for the Removal of Cadmium, Copper, Lead and Zinc from Artificially Contaminated Soil using EDTA, Rhamnolipids, and Soapnut
}

\author{
Elijah Chibuzo Ugwu, Bhaskar Sen Gupta, Adeloye Adebayo and Nadia Martínez-Villegas
}

\section{ABSTRACT}

Environmental contamination caused by high contents of toxic metals in the soil is a global concern. Soil washing using chelating agents and saponin can enhance metal removal from contaminated soils through the formation of soluble metal complexes, mobilization, and extraction with the washing solutions. Column experiments were conducted in this study to assess the feasibility of using a chelate (EDTA), a saponin (soapnut) and microbial (rhamnolipid) cleaning agents to enhance the removal of $\mathrm{Cd}, \mathrm{Cu}, \mathrm{Pb}$ and $\mathrm{Zn}$ from sandy loam contaminated soils. The cumulative removal of $\mathrm{Cd}$ after 10 pore volumes were $\mathbf{7 4 . 0 5}$ for EDTA, 63.08 for rhamnolipids, and 69.07 for soapnut. The cumulative removals of $\mathrm{Cu}$ after washing with 10 pore volumes were $\mathbf{6 4 . 7 2 \%}$ for soapnut, $\mathbf{6 1 . 5 8 \%}$ for rhamnolipids and $61.95 \%$ for EDTA. Also, the cumulative removals of $\mathrm{Pb}$ were $62 \%$ for soapnut, $59.65 \%$ for rhamnolipids and $59.95 \%$ for EDTA after washing with 10 pore volumes. The cumulative removals of $\mathrm{Zn}$ after washing with 10 pore volumes were $\mathbf{6 8 . 5 4 \%}$ for soapnut, $\mathbf{6 2 . 6 5 \%}$ for rhamnolipids and $\mathbf{6 6 . 0 8 \%}$ for EDTA. The performance of these experiments demonstrates that the application of these cleaning agents in in-situ soil remediation can be effective alternative to exsitu remediation.

Keywords: Heavy metals; Saponin; Contaminated soil; Soil washing; Biosurfactant; Pore volume.

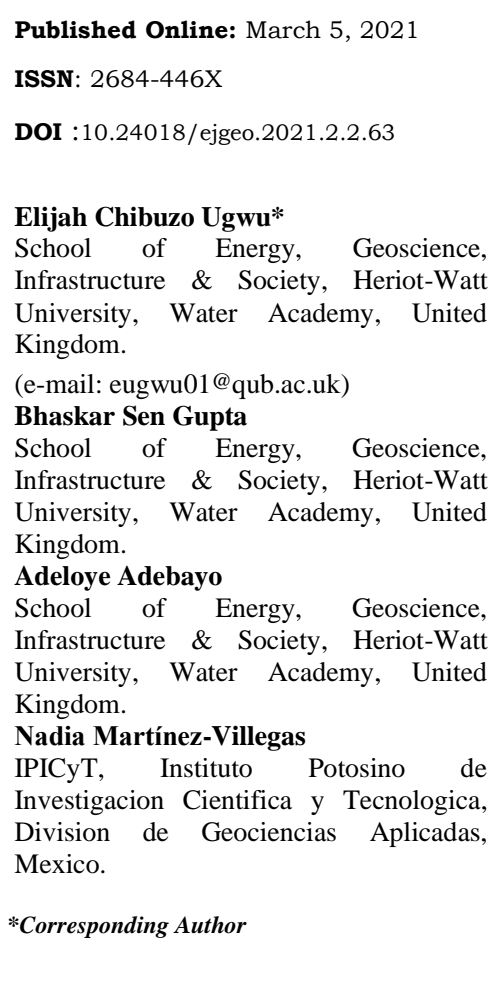

\section{INTRODUCTION}

The global challenges of toxic metal contamination of the soil and poisoning of the food chain along with their effects on human health have been widely reported [1]-[4]. Anthropogenic activities such as mining, smelting, industrial wastes, the use of chemicals and fertilizer in agriculture, solid wastes disposal and landfilling have been reported to be responsible for the unabated increase in heavy metal deposition to the soil [4], [5]. Heavy metals are very toxic, non-biodegradable and could persist in the soil for very long time [6]-[8]. Besides the contamination of food and water sources, polluted soils usually lose their values, which usually results in the limitation of their uses due to regulatory restrictions on potential use for agriculture, residential, recreational, social and commercial activities [9]. The most frequently found heavy metals include lead, nickel, mercury, arsenic, chromium, cadmium, zinc, and copper [10]. Most of these heavy metals exist as cationic (lead, zinc and copper) and anionic (arsenic and chromium) forms in the soil that are moderately contaminated [10]. The mobility of these heavy metals within the vicinity of contaminated sites and from soil into the surface and groundwater sources are strongly influenced by both the soil type, metals speciation, physicochemical properties and biological activities [11].

Remediation of heavy metal contaminated soils has become a serious concern and has created huge challenges globally in recent years. Remediation of contaminated soils is targeted at reducing the risk associated with contaminants and improving the environmental safety while complying with the regulatory requirements [12]. Soil remediation technologies are developed and used to reduce, immobilize, stabilize, confine, or eliminate soil contaminants [3], [13].

The techniques so far applied to remediate contaminated soils can be grouped into two types (in-situ and ex-situ) and can be carried out by three basic methods, namely: physical, chemical, and biological methods [13], [14]. Selection of soil remediation techniques depends on the nature and properties of the soil and the nature, forms and concentrations of the pollutant [12], [15]. However, soil properties differ greatly, even within small areas and therefore, proper feasibility studies and risk assessment are needed before selecting one or more remediation technologies. Thus, a remediation technology that addresses the permanent removal of pollutants without any significant adverse effect on the environment is highly sought for. 
Among various technologies that are available for cleaning-up soil contamination, soil washing ensures permanent removal of heavy metals and organic contaminants from the soils [7], [8], [16]. Soil washing is usually performed ex-situ by excavating the contaminated soil portion and taking it to a washing site where the contaminants would be removed using water, steam, chelates and recently surfactant. The ex-situ practice of soil washing has lots of limitations:

1. Excavating contaminated soil and transferring to treatment plant is labour intensive, time consuming and may result in cross-contamination.

2. Economically, it can be very expensive due to the involvement of large equipment and consumption of energy.

3. Environmentally, it can be a source of soil and air pollution; it can also lead to imbalance of ecosystems as well as the destruction of microorganisms and micronutrients. Therefore, ex-situ clean-up by soil washing is not sustainable.

However, soil clean-up can also be performed in-situ by flushing or flooding the contaminated soil with washing solutions with the aim of extracting the pollutants from the soils. The limitations of in-situ washing are:

1. Application of in-situ washing depends on the permeability soil as soils with less permeability are not suitable for this process. Alternative remediation of such soils is excavating the contaminated portions and clean them insitu.

2. Possibilities of groundwater migration of the pollutant. Drainage channels and out-let pumps are usually applied as control measure that would prevent the migration of contaminant to the groundwater while washing in-situ.

Soil cleaning technologies commonly utilize surfactant solutions to remove the contaminants during the washing process. Surfactants are surface active compounds or agents which can lower the surface tension between two liquids, solid and liquid or liquid and gas. Surfactants can be produced from both chemical and biological means. Chemical, surfactants are known as synthetic surfactants while biological produced surfactants (plants, animals and microorganisms) are called biosurfactant [17], [18].

Several chemical reagents and biological extracts have been studied for their effectiveness in removing heavy metals and organic contaminants from soil. Saponin, a plant-based surfactant with distinctive foaming characteristics is gaining attention due to its potential in remediation of both organic and heavy metal contaminated soils. Some recently reported works have focused on the production and use of saponin from different species of plants as cleaning agents [1], [19]. Sapindus mukorossi (soapnut) was applied for the removal of arsenic from iron rich soils, cadmium and phenanthrene [20], as well as $\mathrm{Cu}, \mathrm{Pb}$ and $\mathrm{Zn} \mathrm{[1].} \mathrm{Rhamnolipids,} \mathrm{a} \mathrm{class} \mathrm{of}$ microbial cleaning agent have been studied widely and applied in soil remediation [21]. EDTA is a soluble chemical agent, which has many commercial applications including chelating and metal complexing in soil remediation [8].

Although, some of these washing agents are known to be effective in soil cleaning, column studies on the use of these three washing agents for removal of multi-metal spiked soils have not been reported. Therefore, a laboratory column experiment was set-up to simulate in-situ washing or heapleaching process, so as to assess the performance of soapnut, rhamnolipids and EDTA solutions on heavy metal spiked soil, and to evaluate them based on their removal efficiencies. The objectives of this experiment are:

1. To conduct soil washing in column to simulate in-situ remediation of soil using different washing agents.

2. To determine the removal efficiency of washing agents (EDTA, rhamnolipids, and soapnut) on soil spiked with $\mathrm{Cd}$, $\mathrm{Cu}, \mathrm{Pb}$ and $\mathrm{Zn}$.

3. To study the impacts of these washing agents on the soil after remediation using scanning electron microscope (SEM).

\section{MATERIAL AND MethodS}

\section{A. Soil Samples and Characterization}

Fine sand and garden topsoil were procured from a garden centre in Edinburgh. The soil samples were air dried and screened through $2 \mathrm{~mm}$ sieve to remove coarse sand and other aggregates. The soil was then homogenized by thoroughly mixing together and stored in plastic bags for subsequent use. A range of relevant soil parameters, such as $\mathrm{pH}$, electrical conductivity, bulk density, porosity, particle size distribution, cation exchange capacity (CEC), organic matter and moisture content were determined following standard method (Table I). The $\mathrm{pH}$ values were measured using $\mathrm{pH} / \mathrm{ORP}-999$ probe. $20 \mathrm{~g}$ of soil was added to $50 \mathrm{ml}$ of distilled water before being shaken and left for 1 hour prior to taking measurements with the probe following the standard method [22]. The bulk density and porosity of the soils were determined using Gravimetric method and methods proposed by [23]. The standard oven drying method was used to determine the soil moisture content. The organic matter content of each sample was analyzed by loss of weight by ignition. The results of the initial soil characteristics are shown in Table I.

\section{B. Soil Contamination Procedure}

Method used in this work was adopted from previous reports on similar studies [3], [24]. The soil spiking with heavy metals was carried out to increase the contents of $\mathrm{Cd}$, $\mathrm{Pb}, \mathrm{Cu}$, and $\mathrm{Zn}$. About $4 \mathrm{~kg}$ of dry soil were contaminated with 3 litres of distilled water containing dissolved cadmium nitrate, $\mathrm{Cd}\left(\mathrm{NO}_{3}\right)_{2} .4 \mathrm{H}_{2} \mathrm{O}$, copper sulphate $\mathrm{Cu}\left(\mathrm{SO}_{4}\right)_{2}$, zinc nitrate, $\mathrm{Zn}\left(\mathrm{NO}_{3}\right)_{2}$. $6 \mathrm{H}_{2} \mathrm{O}$ and lead nitrate, $\mathrm{Pb}\left(\mathrm{NO}_{3}\right)_{2}$. The metallic oxides were in pure forms as supplied by Fisher Scientific Chemicals Ltd, UK. The heavy metals solution was thoroughly mixed with the soil into a slurry, before being left to age and cure for more than 6 months with frequent mixing. After the period of curing, the slurry was air dried to a constant mass. The soils (un-spiked and spiked soils) were digested using a standard method (EPA 3050B). The soils were analyzed using inductively coupled plasma optical emission spectroscopy (ICP OES). The values of heavy metals after ICP OES analysis (Table III) were approximately $700,1000,3000$, and $7000 \mathrm{mg} / \mathrm{kg}$ for $\mathrm{Cu}, \mathrm{Pb}$ and $\mathrm{Zn}$ respectively. These values were far above the threshold values (Table III) of 4, 150, 100, $300 \mathrm{mg} / \mathrm{kg}$ and 15, 600, 600, $1000 \mathrm{mg} / \mathrm{kg}$ for agricultural and industrial soils respectively [25]. 
TABLE I: ESSENTIAL PHySICOCHEMICAL PROPERTIES OF THE ORIGINAL

\begin{tabular}{|c|c|c|}
\hline \multicolumn{3}{|c|}{ SOILS } \\
\hline Soil properties & Values & Methods \\
\hline $\mathrm{pH}$ & 7.21 & US EPA method 9045D \\
\hline $\begin{array}{c}\text { Electrical conductivity (EC } \\
\mathrm{dS} / \mathrm{m} \text { ) }\end{array}$ & 1.2 & $\begin{array}{l}\text { Violante and Adamo } \\
\text { method [22] }\end{array}$ \\
\hline Soil moisture content (\%) & 9.2 & ASTM D2216 \\
\hline $\mathrm{CEC}\left(\mathrm{meq} 100 \mathrm{~g}^{-1}\right)$ & 8.3 & Ammonium acetate method \\
\hline Bulk density $\left(\mathrm{g} / \mathrm{cm}^{3}\right)$ & 1.43 & Gravimetric method \\
\hline Porosity & 49 & [23] \\
\hline Organic matter content (\%) & 2.4 & Loss of weight by ignition \\
\hline Sand $(\%)$ & 80 & \\
\hline Topsoil (\%) & 20 & USDA classification \\
\hline Heavy Metal content & & \\
\hline Lead (mg/L) & 1.17 & \\
\hline Copper $(\mathrm{mg} / \mathrm{L})$ & 14.65 & Digestion USEPA 3050B \\
\hline Zinc $(\mathrm{mg} / \mathrm{L})$ & 34.21 & and measured by ICP-OES \\
\hline Cadmium (mg/L) & 2.09 & \\
\hline
\end{tabular}

TABLE II: EXPERIMENTAL FACTORS AND VALUES

\begin{tabular}{ccc}
\hline Factors & Values & Unites \\
\hline Temperature & \pm 25 & ${ }^{\circ} \mathrm{C}$ \\
Concentration & 5 & $\%$ \\
of agents & 5 & \\
pH & 3 & \\
Bulk density & 0.8 & $\mathrm{~g} / \mathrm{cm}^{3}$ \\
Column height & 17.5 & $\mathrm{~cm}$ \\
$\begin{array}{c}\text { Column } \\
\text { diameter }\end{array}$ & 5 & $\mathrm{~cm}$ \\
$\begin{array}{c}\text { Porosity } \\
\text { Pore volume }\end{array}$ & 68 & $\%$ \\
$\begin{array}{c}\text { (PV) } \\
\text { Soil dry } \\
\text { weight }\end{array}$ & 146.8 & $\mathrm{~cm} 3$ \\
Flow rate & 200 & $\mathrm{~g}$ \\
\hline
\end{tabular}

TABLE III: HEAvy METAL CONCENTRATIONS IN THE SPIKED SOIL USED FOR THE EXPERIMENTS (FIGURES WERE APPROXIMATED; $\mathrm{N}=3$ )

\begin{tabular}{ccccc}
\hline & & Measured & $\begin{array}{c}\text { Threshold } \\
\text { value for } \\
\text { Agriculture }\end{array}$ & $\begin{array}{c}\text { Threshold } \\
\text { value for } \\
\text { industries }\end{array}$ \\
\cline { 2 - 5 } $\mathrm{Cu}$ & $\mathrm{mg} / \mathrm{kg}$ & 1000 & 150 & 600 \\
$\mathrm{~Pb}$ & $\mathrm{~m} / \mathrm{kg}$ & 3000 & 100 & 600 \\
$\mathrm{Zn}$ & $\mathrm{mg} / \mathrm{kg}$ & 7000 & 300 & 1000 \\
\hline
\end{tabular}

\section{Preparation of Washing Solutions}

Certified pure dry organic soapnut powder was supplied by Davis Finest, Hampshire, UK, while EDTA and rhamnolipids were supplied by Fisher Scientific Chemicals Ltd, UK, which were used as cleaning agents. A stock solution of $10 \%$ concentration of each of the agents was prepared by weighing $10 \mathrm{~g}$ powder and adding to $100 \mathrm{ml}$ of distilled water. The solution was stirred for $3 \mathrm{~h}$ at room temperature and then filtered after centrifuging at $3000 \mathrm{rpm}$ for $25 \mathrm{~min}$ following a modification of procedures used by [26]. The filtrate was diluted to the desired concentration and used without further purification. The solutions were prepared when needed and used freshly without storage to avoid corrosion.

\section{Procedure for Column Soil Washing Studies}

The advantages of in-situ remediation of contaminated soil by using soil washing techniques cannot be over emphasized [27]. In this study, column washing was setup to represent an in-situ washing techniques as shown in Fig. 1. This technology has been performed successfully in field remediation of paddy rice [28]. Distilled water as well as the $5 \%$ concentrations of different washing agents was used as washing fluids. About $200 \mathrm{~g}$ of dried contaminated soil was packed into plastic columns. The soil bulk density of $0.8 \mathrm{~g} / \mathrm{cm}^{3}$ was achieved by the configuration. The column height was $17.5 \mathrm{~cm}$ with the internal diameter of $5 \mathrm{~cm}$. The porosity of the soil column was $68 \%$ and the pore volume (PV) was $146.8 \mathrm{~cm}^{3}$. Washing fluids were introduced into the soil column at the rate of $5 \mathrm{ml} / \mathrm{min}$. 10 pore volumes of the surfactants solution were used for the column washings. A down-flow mode washing was established by pumped washing solution from the beaker into the soil (Fig. 1). After each pore volume, the effluent is collected and centrifuged at $9000 \mathrm{~g}$ for $15 \mathrm{~min}$ [29]. The initial $\mathrm{pH}$ of the surfactant solution was modified either by addition of hydrochloric acid or sodium hydroxide [15]. The supernatants were collected after filtration using Whatman filter paper. The samples were preserved with 1 drop of nitric acid and stored for ICP-OES analysis. The details of the experimental conditions and variables are shown in Table II. Distilled water was used as a benchmark. The response was recorded as percentage of metals removed from the washing experiment and calculated using a similar equation as reported by [3].

Percentage metal removed $(\%)=\frac{C_{1} V_{1}}{C_{S} M_{S}} \times 100$

where $\mathrm{C}_{1}(\mathrm{mg} / \mathrm{l})$ and $\mathrm{C}_{\mathrm{S}}(\mathrm{mg} / \mathrm{kg})$, are the concentrations of metal in supernatant and soil respectively; $\mathrm{V}_{\mathrm{l}}$ is the volume of supernatant (litres) and $\mathrm{M}_{\mathrm{S}}$ is the dry mass of the soil $(\mathrm{kg})$. The $\mathrm{pH}$ of the solutions before washing and supernatants after washing was recorded. To ensure precision, all the experiments were performed in three replicates and results were presented as averages of the replication values [30]. Details of experimental standards and variables are given in Table II.

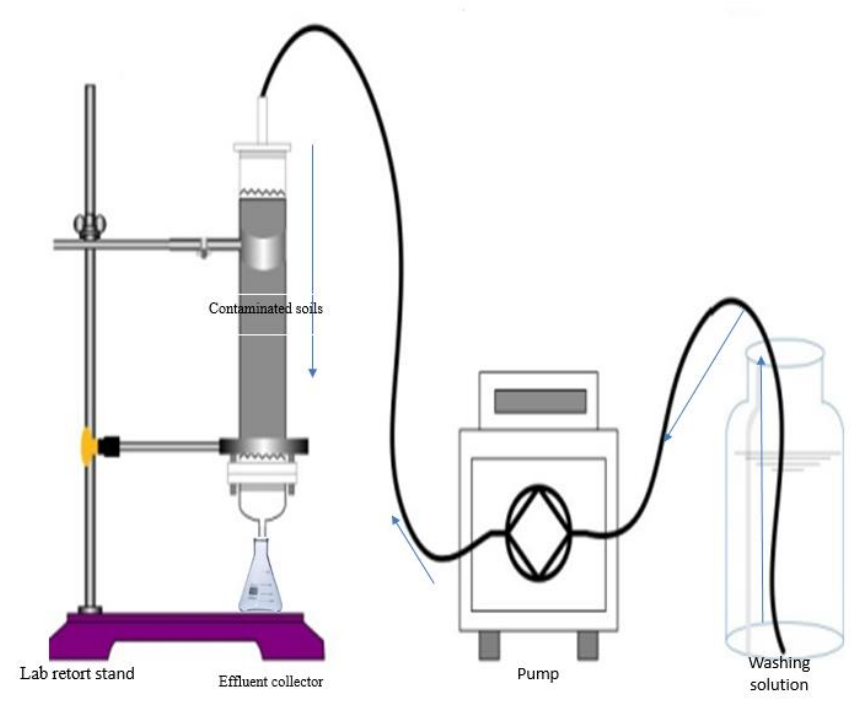

Fig. 1. Diagram of soil column washing experimental setup.

\section{RESUltS AND DisCUSSIONS}

\section{A. Physicochemical Analysis of Soil}

Table I shows the results of the physicochemical properties of the virgin soil. The soil used in this study is made up of fine sand and topsoil. The topsoil consists of loam soil and organic matter used as soil amendment for both garden and other agricultural needs. The soil combination is a good example of a typical soil used for cultivation of crop and can be classified as loamy sand according to USDA soil classification triangle. Sandy soils are known to have low 
retention capacity for both water and heavy metals. In other hand, the addition of topsoil will retain water and heavy metals because of the organic matter content which is known to have great affinity for heavy metals and retention of water as well [3].

Physicochemical test further shows that the soil $\mathrm{pH}$ is near neutral (Table I). The neutral $\mathrm{pH}$ generally favours the growth of plants, while a lower soil $\mathrm{pH}$ is necessary for heavy metal desorption from soil. Electrical conductivity (EC) is the measure of salinity of the soil. High EC is not good for the survival of plants as well as microorganisms in the soil. The EC value of $1.2 \mathrm{dS} / \mathrm{m}$ is within normal range for agricultural soil. The soil has low organic matter due to the greater percentage of sand; organic matter is known to have great binding strength with copper and other metals. CEC is the capacity of soil to retain a particular group of nutrients called cations. It is known that CEC comes from clay and organic matter present in the soil. Therefore, low value of CEC was due to low organic matter. Thus, the low values of EC, CEC, organic matter and moderate porosity obtained from the physiochemical analysis of the soil mean that the soil was permeable and will enhance leachability of heavy metals and the possibilities of remediation by soil washing [3], [23]. Soil analysis also revealed very low levels of heavy metal concentration and thus the spiking with a lead nitrate was required to increase the level of heavy metal concentration.

\section{B. Cadmium}

Cumulative removal efficiency for $\mathrm{Cd}$ by distilled water, biosurfactants and EDTA are shown in Fig. 2. Distilled water removed a cumulative of $12.78 \% \mathrm{Cd}$ after $10 \mathrm{PV}$. This accounts for the amount of metal that can be removed by physical treatment. Washing with distilled water provided an insight into the fractions of metals that are held loosely and can be easily desorbed into the soil-solution matrix [13]. Washing with $5 \%$ of EDTA improved the Cd extraction maintaining higher yield among the washing agents and achieving a cumulative removal efficiency of $74.05 \%$ after 10 PV. The removal of Cadmium from soil by EDTA is said to be controlled by rapid desorption of weakly held Cd-soil surface which complexes and dissolves into a loosely held metals precipitates in the soil interstices [13], [31].

According to [32], Cd removal could be as result of the capacity of EDTA to effectively adsorb, dissolute and solubilize the organic matter that binds with the $\mathrm{Cd}$ with the soil. EDTA is known to be an effective chelating agent, which can complex with most of the metals. However, EDTA leaves residues behind which persist in the natural environment after remediation of soil. Thus, biosurfactants, which can provide an alternative to EDTA, and at the same time cause no harm to the natural environment after remediation processes, deserve more attention. Apart from leaving persistent residues behind after remediation, EDTA and most of synthetic chelates are expensive compared to saponin.

Fig. 2 also shows that flushing of the contaminated soil with rhamnolipids solution removed $63.08 \%$ of Cd after 10 PV. This result was lower than that obtained with EDTA, soapnut and but better than obtained with distilled water. Previous reports indicate that the possible mechanisms for the extraction of metals by rhamnolipids include ion exchange, precipitation-dissolution, ion exchange and association [7]. It is known also that heavy metals can be removed by surfactants through the formation of micelles and subsequent complexes on the soil surface [5]. When there is lower interfacial tension caused by surfactant micelles, heavy metal-surfactant complexes will be detached from the soil into the soil solution and could precipitate out of the solution.

Few column studies have been reported on $\mathrm{Cd}$ flushing with rhamnolipid and the present result is comparable with the reported data. [21] conducted a series of column experiments to evaluate the feasibility of using rhamnolipid to flush heavy metals including $\mathrm{Cd}$ from contaminated sandy soils. The study reported that rhamnolipid biosurfactant liquid solution removed $61.7 \%$ of Cd after $20 \mathrm{PV}$ of flushing as against $18 \%$ removed by distilled water. Similarly, [7] reported that di-rhamnolipid biosurfactant produced by Pseudomonas aeruginosa strain BS2 was capable of removing $92 \%$ of $\mathrm{Cd}$ from artificially contaminated soil after $36 \mathrm{hr}$ of flushing while distilled water removed $2.7 \%$. Both studies observed that the use of rhamnolipid showed no toxic effect on the soil microorganisms and have no structural damage to the soil. Thus, confirming the potential for possible application of rhamnolipid to heavy metal remediation.

The cumulative result of Cd flushing (Fig. 2) shows that soapnut removed $69.07 \%$. after 10 PVs, plant-based biosurfactants have been reported to be effective cleaning agents and have been used in hair care products [33]. Similar applications of plant-based biosurfactants show that saponin readily forms complexes between carboxylic group and $\mathrm{Cd}$ in aqueous solutions [34]. [2] reported that Tannic acid and saponin are both comparable in removing $\mathrm{Cd}$ and $\mathrm{Pb}$ from soil in batch experiments. Nevertheless, this study revealed that soapnut can be effective in flushing Cd contaminated soils.

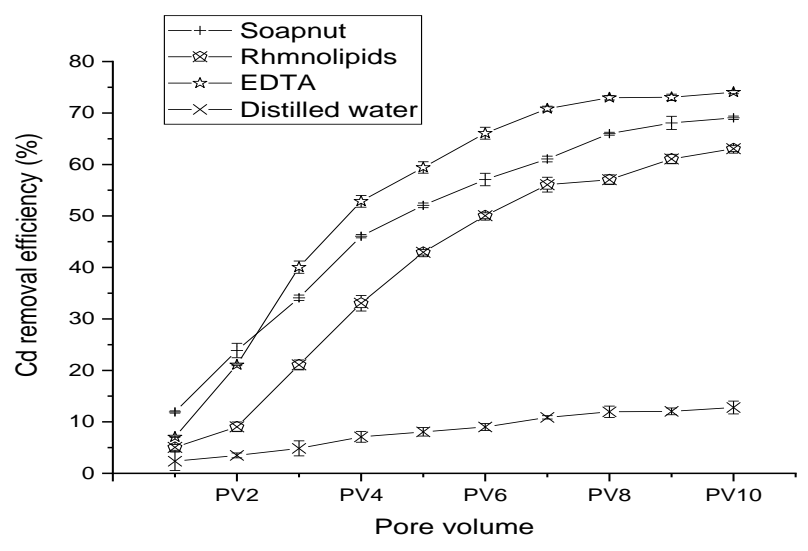

Fig. 2. Cumulative removal efficiency of distilled water, EDTA, rhamnolipid and soapnut from Cd contaminated soil.

\section{Copper}

Results for cumulative $\mathrm{Cu}$ removal (Fig. 3) show that Distilled water removed $13.65 \%$ after 10 PVs. The pattern for $\mathrm{Cu}$ extraction by distilled water appeared almost linear or gradual approach to steady state, which is absolutely different from the other three extracting agents. This is because after the first 3 PVs, the subsequent addition of the distilled water did not yield a reciprocal $\mathrm{Cu}$ removal. This could suggest that the amount of weakly bond $\mathrm{Cu}$ available in the contaminated soil has been depleted after 3 PVs. EDTA obtained a cumulative efficiency of $61.96 \%$ of $\mathrm{Cu}$ after $10 \mathrm{PVs}$. These 
results were less than what was reported previously in $\mathrm{Cd}$ flushing. Although EDTA has great affinity for $\mathrm{Cu}$ and binds strongly in solutions, there seems to be a situation where addition of excess amount of EDTA will lead to an increased competition for electrostatic attraction on protonated amine groups which could lead to a decrease in sorption capacity in the column [35]. This could explain the low removal efficiency obtained. There is currently no or few studies available on the column flushing of $\mathrm{Cu}$ contaminated soil using EDTA. Therefore, comparison of the results obtained in this experiment is difficult.

Fig. 3 shows that rhamnolipid removed a cumulative percentage of $61.57 \%$ of $\mathrm{Cu}$ from the contaminated soil after $10 \mathrm{PV}$ s flushing. This result seems to be similar to what was obtained when the rhamnolipid was used to flush $\mathrm{Cd}$ at the same condition. Rhamnolipid is known to have electrostatic attraction and strong affinity for heavy metals including $\mathrm{Cd}$, $\mathrm{Pb}$ and $\mathrm{Zn}$ [36]. There is none or little information of application of rhamnolipid in column flushing for $\mathrm{Cu}$ contaminated soil at present.

Fig. 3 also shows that soapnut removed $64.72 \%$ of $\mathrm{Cu}$ after 10 PVs. saponin performed better than the EDTA in the removal of $\mathrm{Cu}$. Available reports show that saponin molecules can form complexes with $\mathrm{Cu}, \mathrm{Pb}$ and $\mathrm{Zn}$ in aqueous solutions using the carboxyl group on their hydrophilic head [37]. This suggests that the removal of $\mathrm{Cu}$ from the contaminated soil by soapnut may have been the result of the carboxyl groups produced by the saponin and the complexes formed with $\mathrm{Cu}$. Previous studies on column soil washing experiments by [38], reported successful removal of arsenic and heavy metals $(\mathrm{Pb}, \mathrm{Cu}$ and $\mathrm{Zn}$ ) from mine tailings. The study assessed the feasibility of using humic acid to mobilize arsenic and heavy metals from an oxidized $\mathrm{Pb}-\mathrm{Zn}$ mine tailings sample collected from Bathurst, New Brunswick, Canada. The results show that mobilization of As, $\mathrm{Cu}, \mathrm{Pb}$ and $\mathrm{Zn}$ reached 97, 35, 838 and $224 \mathrm{mg} \mathrm{kg}^{-1}$, respectively after 70 Pvs of flushing.

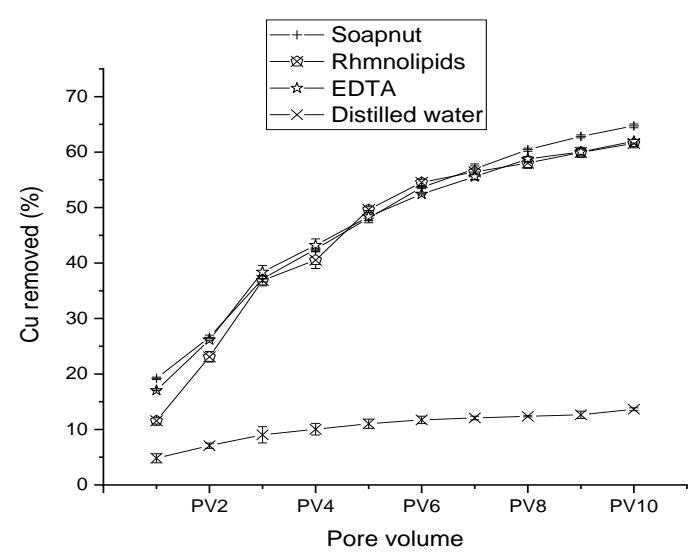

Fig. 3. Cumulative removal efficiency of distilled water, EDTA, rhamnolipid and soapnut from $\mathrm{Cu}$ contaminated soil.

\section{Lead}

It is well known that $\mathrm{Pb}$ has great affinity for soil organic matters and mineral oxides and tends to adsorb onto soil surfaces by chemisorption process in lead contaminated soil [13], [31]. This can explain why $\mathrm{Pb}$ removal was the lowest among the four metals studied in column experiments. Fig. 4 shows that Distilled water removed a cumulative amount of $6.96 \%$ after $10 \mathrm{PVs}$. This result is in agreement with previous study [13] that reported the removal of $12 \% \mathrm{~Pb}$ after $300 \mathrm{PVs}$. The strong bond that was formed between $\mathrm{Pb}$ and the organic matter in the soil contributed to removal efficiency obtained in the flushing experiments. It was observed (Fig. 4) that EDTA followed a rapid $\mathrm{Pb}$ removal in first few PVs, then gradual to linear removal pattern to a total cumulative removal efficiency of $59.95 \%$ after 10 PVs. This removal pattern is in agreement with that reported in a previous study [39]. [13] also reported that $\mathrm{Na}_{2}$ EDTA forms strong complexes with $\mathrm{Pb}$ than with $\mathrm{Cd}, \mathrm{Cr}$ and $\mathrm{Zn}$.

Fig. 4 also shows that after 10 PVs, soapnut obtained the highest cumulative removal of $\mathrm{Pb}$ in this experiment. The cumulative removal efficiency of $62.78 \%$ was obtained by using soapnut, this was slightly higher than $59.63 \%$ obtained by rhamnolipid under the same conditions. This observation shows that biosurfactant performed better than EDTA and distilled water in this experiment. After $36 \mathrm{~h}$ of leaching, [7] removed a cumulative total of $88 \%$ of $\mathrm{Pb}$ from artificially contaminated soil using di-rhamnolipid biosurfactant produced by Pseudomonas aeruginosa strain BS2. Studies have suggested the likely mechanisms for $\mathrm{Pb}$ removal by biosurfactant are formation of micelles, complexion with metals on the soil surface, ion exchange and precipitation of sorbed metals onto solution for possible extraction [21]. Lower removal of $\mathrm{Pb}$, has been attributed to its less mobility in contaminated soil [2]. For a batch experiment, saponin was reported to have removed $21 \%$ of $\mathrm{Pb}$ as against $81 \%$ of $\mathrm{Cu}$ removed under the same conditions [2]. This means that more of $\mathrm{Pb}$ in the contaminated soil were tightly bound to the soil organic matter than $\mathrm{Cu}$.

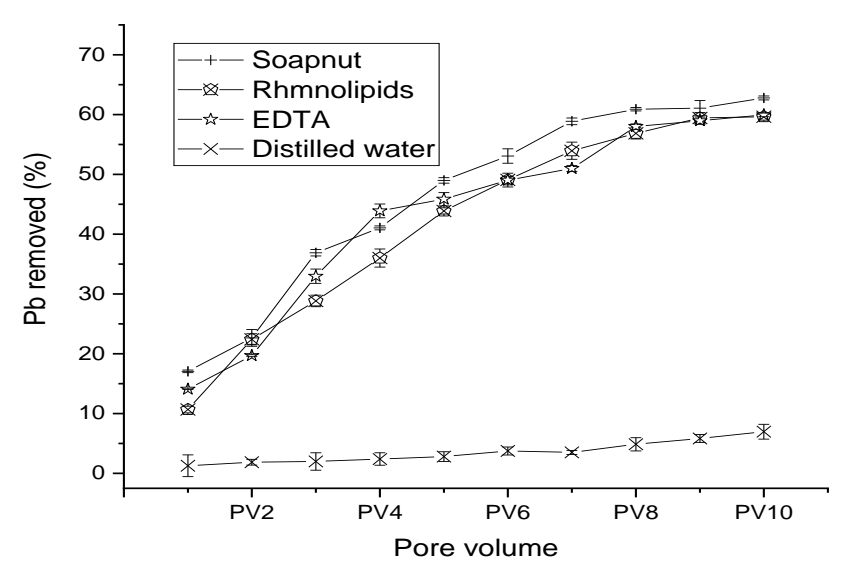

Fig. 4. Cumulative removal efficiency of distilled water, EDTA, rhamnolipid and soapnut from $\mathrm{Pb}$ contaminated soil.

\section{E. Zinc}

Fig. 5 shows the cumulative removal of $\mathrm{Zn}$ from the soil by flushing it with distilled water, 5\% EDTA, 5\% soapnut, $5 \%$, and $5 \%$ rhamnolipid solutions at $\mathrm{pH}$ of 3 . After $10 \mathrm{PVs}$, distilled water removed a cumulative amount of $16.64 \%$ of the $\mathrm{Zn}$ from the contaminated soil, indicating that $\mathrm{Zn}$ was bound strongly with the soil. Soapnut removed a cumulative amount of $66.08 \%$ while EDTA removed a cumulative amount of $62.76 \%$ of $\mathrm{Zn}$ after $10 \mathrm{PVs}$ flushing. Soapnut removed more $\mathrm{Zn}$ than that removed by EDTA, although 
EDTA is anionic unlike the saponin which is non-ionic, the cumulative removal efficiency of saponin solution is higher than that of EDTA. This suggests that ionic exchange and interaction played less significant role than micelles formation by saponin which reduced the surface tension between soil particles and washing solutions and enabled solubilization of $\mathrm{Zn}$ from the soil matrix [40].

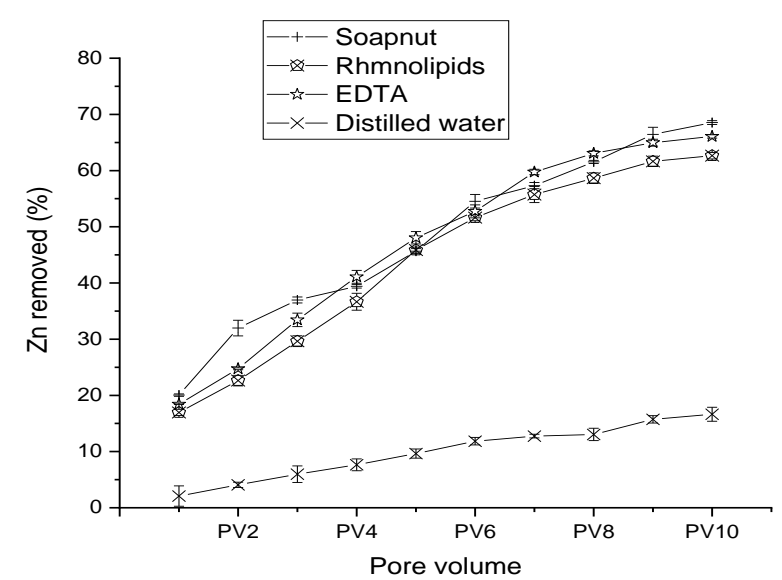

Fig. 5. Cumulative removal efficiency of distilled water, EDTA, rhamnolipid and soapnut from $\mathrm{Zn}$ contaminated soil.

Fig. 5 also shows that rhamnolipid solution could remove close to $61.65 \%$ of $\mathrm{Zn}$ from the contaminated soil after 10 $\mathrm{PVs}$. It was observed that the $\mathrm{Zn}$ extraction increased simultaneously with increase in PVs for all the washing agents used. The low mobility of $\mathrm{Zn}$ in soil suggests the poor cumulative removal efficiency obtained after 10 PVs. Previous studies reported that $\mathrm{Zn}$ was the least removed among $\mathrm{Cd}, \mathrm{Cu}$, and $\mathrm{Pb}$ [25], [30], [41]. [13] reported that unlike $\mathrm{Pb}, \mathrm{Zn}$ adsorption to the soil matrix is stronger and they suggested a continuous extraction by adding fresh washing solutions to obtain a higher removal efficiency. Similarly, [25] shows that extraction of $\mathrm{Zn}$ with saponin and tannic acid in batch experiments obtained removal efficiency for $\mathrm{Zn}$ (54 and $48 \%)$ as against $\mathrm{Pb}(21$ and $61 \%)$ respectively. In this study, the removal efficiencies obtained by the washing agents for Zn were slightly higher for than that obtained for $\mathrm{Pb}$.

\section{F. Study of Soil Structure before and after Washing}

SEM analysis was carried out to understand the structural changes that occurred in the soil after washing with distilled water, biosurfactants and EDTA in column experiments. The results in Fig. 6 indicate the changes that occurred after the soil was spiked, and also when it was washed with distilled water, biosurfactants and EDTA. However, the extent of structural changes and corrosion that occurred were different and depended on the washing substance used. For instance, there were mild changes and corrosion observed on the soil surface after it was washed with soapnut and rhamnolipid compare to washing with EDTA. Although, distilled water removed small amounts of the heavy metal, it was observed through the SEM to have structural changes on the soil. Even the spiked soil looked very different from the original soil because of changes that occurred during the soil contamination.

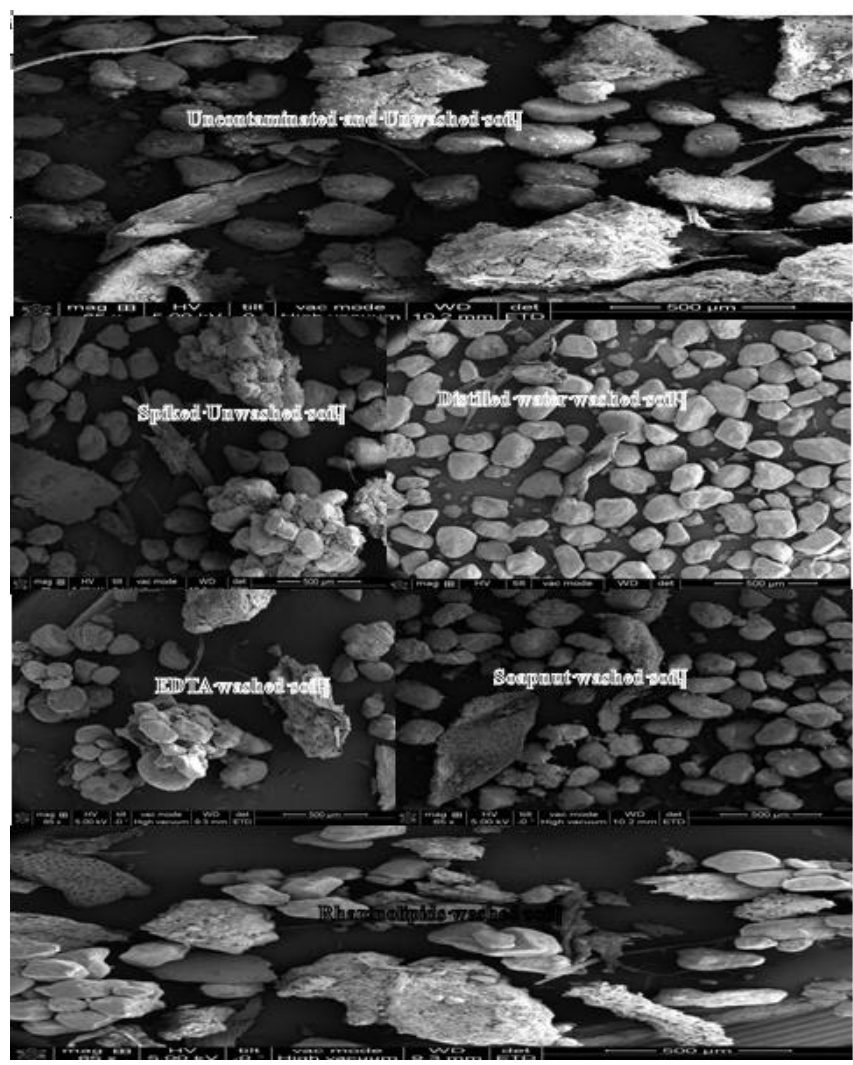

Fig. 6. SEM images of original soil, contaminated soils and soil washed with distilled water, Biosurfactants and EDTA.

[42] reported that dissolution did not affect the soil mineral components such as $\mathrm{Ca}, \mathrm{Mg}, \mathrm{Al}, \mathrm{Si}$ and $\mathrm{Fe}$ after soil was washed with soapnut and phosphate to remove arsenic. In this study, some of the organic matter of the soil seems to have been lost or distorted when washed with EDTA. Lower pH of the EDTA and soapnut might have been the reason behind this observation. Soapnut and rhamnolipid are satisfactory washing agents in terms of preventing soil structural changes. Structural changes were also observed through SEM on the contaminated soil and the washed soil. The changes were attributed to the distortion of the original soil as they occurred irrespective of the washing solution used. Soapnut and rhamnolipid are likely to be the most environment friendly washing agents in terms of preserving soil quality.

\section{CONCLUSIONS}

The performance of distilled water, EDTA and biosurfactants for the removal of $\mathrm{Cd}, \mathrm{Cu}, \mathrm{Pb}$ and $\mathrm{Zn}$ in column experiments have been studied. The results demonstrate that in-situ soil remediation can be an effective alternative to ex-situ soil washing. Removal of heavy metals can be achieved by using environment-friendly washing agents such rhamnolipid, and soapnut. Although column experiment requires higher volume of washing solution than batch washing, use of soapnut which is cheaper than EDTA could make the whole process more economical. This study suggests that in-situ remediation is an ideal method of soil cleaning with the application of biosurfactants as washing agents. The usual excavation of contaminated soil and washing it outside the site has enormous disadvantages of cross-contamination and high cost which could be avoided by washing in-situ. 


\section{REFERENCES}

[1] Maity, J.P., et al., Evaluation of remediation process with soapberry derived saponin for removal of heavy metals from contaminated soils in Hai-Pu, Taiwan. Journal of Environmental Sciences, 2013. 25: p. 1180-1185.

[2] Gusiatin, Z.M., K. Bułkowska, and T. Pokój, Tannic acid as a costeffective substitute for saponin in soil remediation. Environmental Biotechnology, 2014. 10.

[3] Wuana, R., F. Okieimen, and J. Imborvungu, Removal of heavy metals from a contaminated soil using organic chelating acids. International Journal of Environmental Science \& Technology, 2010. 7(3): p. 485 496.

[4] Li, C., et al., A Review on Heavy Metals Contamination in Soil: Effects, Sources, and Remediation Techniques. Soil and Sediment Contamination: An International Journal, 2019: p. 1-15.

[5] Sarubbo, L., et al., Some aspects of heavy metals contamination remediation and role of biosurfactants. Chemistry and Ecology, 2015. 31(8): p. 707-723.

[6] Lo, I.M. and X. Yang, EDTA extraction of heavy metals from different soil fractions and synthetic soils. Water, Air, and Soil Pollution, 1999. 109(1-4): p. 219-236.

[7] Juwarkar, A.A., et al., Biosurfactant technology for remediation of cadmium and lead contaminated soils. Chemosphere, 2007. 68(10): p. 1996-2002.

[8] Abumaizar, R. and L.I. Khan, Laboratory investigation of heavy metal removal by soil washing. Journal of the Air \& Waste Management Association, 1996. 46(8): p. 765-768.

[9] Ludmer, Z., et al., Simultaneous removal of heavy metals and organic pollutants from contaminated sediments and sludges by a novel technology, sediments remediation phase transition extraction. Environmental Engineering Science, 2009. 26(2): p. 419-430.

[10] Qiu, R., et al., Removal of trace and major metals by soil washing with Na 2 EDTA and oxalate. Journal of soils and sediments, 2010. 10(1): p. $45-53$.

[11] Hashim, M., et al., Remediation technologies for heavy metal contaminated groundwater. Journal of environmental management, 2011. 92(10): p. 2355-2388.

[12] Wuana, R.A. and F.E. Okieimen, Heavy metals in contaminated soils: a review of sources, chemistry, risks and best available strategies for remediation. Isrn Ecology, 2011. 2011.

[13] Abumaizar, R.J. and E.H. Smith, Heavy metal contaminants removal by soil washing. Journal of Hazardous Materials, 1999. 70(1): p. 71-86.

[14] Khalid, S., et al., A comparison of technologies for remediation of heavy metal contaminated soils. Journal of Geochemical Exploration, 2017. 182: p. 247-268.

[15] Mulligan, C.N., R.N. Yong, and B.F. Gibbs, On the use of biosurfactants for the removal of heavy metals from oil-contaminated soil. Environmental Progress, 1999. 18(1): p. 50-54.

[16] Wang, G., et al., Heavy metal removal by GLDA washing: optimization, redistribution, recycling, and changes in soil fertility. Science of the Total Environment, 2016. 569: p. 557-568.

[17] Soll, R. and F. Blanco, Natural surfactant extract versus synthetic surfactant for neonatal respiratory distress syndrome. The Cochrane Library, 2001.

[18] Soberón-Chávez, G. and R.M. Maier, Biosurfactants: a general overview, in Biosurfactants. 2011, Springer. p. 1-11.

[19 Mukhopadhyay, S., et al., Comparison of a plant based natural surfactant with SDS for washing of As $(V)$ from Fe rich soil. Journal of Environmental Sciences, 2013. 25: p. 2247-2256.

[20] Song, S., L. Zhu, and W. Zhou, Simultaneous removal of phenanthrene and cadmium from contaminated soils by saponin, a plant-derived biosurfactant. Environmental Pollution, 2008. 156(3): p. 1368-1370.

[21] Mulligan, C.N. and S. Wang, Remediation of a heavy metalcontaminated soil by a rhamnolipid foam. Engineering Geology, 2006. 85(1-2): p. 75-81.

[22] Race, M., et al., Copper and zinc removal from contaminated soils through soil washing process using ethylenediaminedisuccinic acid as a chelating agent: A modeling investigation. Journal of Environmental Chemical Engineering, 2016. 4(3): p. 2878-2891.

[23] Urum, K., Biosurfactant enhanced treatment of petroleum oil contaminated soils. 2004, Heriot-Watt University.

[24] Gusiatin, Z.M. and E. Klimiuk, Metal (Cu, $\mathrm{Cd}$ and $\mathrm{Zn})$ removal and stabilization during multiple soil washing by saponin. Chemosphere, 2012. 86: p. 383-391.

[25] Gusiatin, Z., K. Bułkowska, and T. Pokój, Tannic acid as a costeffective substitute for saponin in soil remediation. Environmental Biotechnology, 2014. 10(2): p. 66-72.

[26] Zhang, C., et al., Surfactant screening for soil washing: Comparison of foamability and biodegradability of a plant-based surfactant with commercial surfactants. Journal of Environmental Science \& Health Part A, 1998. 33(7): p. 1249-1273

[27] Wilson, D.J., et al., Groundwater cleanup by in-situ sparging. I. Mathematical modeling. Separation science and technology, 1992. 27(8-9): p. 1023-1041.

[28] Makino, T., et al., A practical soil washing method for use in a Cdcontaminated paddy field, with simple on-site wastewater treatment. Geoderma, 2016. 270: p. 3-9.

[29] Luna, J.M., R.D. Rufino, and L.A. Sarubbo, Biosurfactant from Candida sphaerica UCP0995 exhibiting heavy metal remediation properties. Process Safety and Environmental Protection, 2016.

[30] Zou, Z., et al., The study of operating variables in soil washing with EDTA. Environmental Pollution, 2009. 157(1): p. 229-236.

[31] Yip, T.C., et al., Heavy metal extraction from an artificially contaminated sandy soil under EDDS deficiency: significance of humic acid and chelant mixture. Chemosphere, 2010. 80(4): p. 416-421.

[32] Lo, I.M., et al., Significance of metal exchange in EDDS-flushing column experiments. Chemosphere, 2011. 83(1): p. 7-13.

[33] Jaya Preethi, P., et al., A review on herbal shampoo and its evaluation. Asian J Pharm Ana, 2013. 3(4): p. 153-6.

[34] Hong, K.J., et al., Removal of cadmium and lead from soil using aescin as a biosurfactant. Journal of Surfactants and Detergents, 1998. 1(2): p. 247-250.

[35] Maketon, W., C.Z. Zenner, and K.L. Ogden, Removal efficiency and binding mechanisms of copper and copper-EDTA complexes using polyethyleneimine. Environmental science \& technology, 2008. 42(6): p. 2124-2129.

[36] Franzetti, A., et al., Biosurfactant Use in Heavy Metal Removal from Industrial Effluents and Contaminated Sites. Biosurfactants: Production and Utilization-Processes, Technologies, and Economics, 2014: p. 361.

[37] Maity, J.P., et al., Removal of $\mathrm{Cu}, \mathrm{Pb}$ and $\mathrm{Zn}$ by foam fractionation and a soil washing process from contaminated industrial soils using soapberry-derived saponin: a comparative effectiveness assessment. Chemosphere, 2013. 92(10): p. 1286-1293.

[38] Wang, S. and C.N. Mulligan, Rhamnolipid biosurfactant-enhanced soil flushing for the removal of arsenic and heavy metals from mine tailings. Process Biochemistry, 2009. 44(3): p. 296-301.

[39] Benschoten, J.E.V., M.R. Matsumoto, and W.H. Young, Evaluation and analysis of soil washing for seven lead-contaminated soils. Journal of Environmental Engineering, 1997. 123(3): p. 217-224.

[40] Açıkel, Y.S., Use of biosurfactants in the removal of heavy metal ions from soils, in Biomanagement of metal-contaminated soils. 2011, Springer. p. 183-223.

[41] Kulikowska, D., et al., Humic substances from sewage sludge compost as washing agent effectively remove $\mathrm{Cu}$ and $\mathrm{Cd}$ from soil. Chemosphere, 2015. 136: p. 42-49.

[42] Mukhopadhyay, S., et al., Arsenic removal from soil with high iron content using a natural surfactant and phosphate. International Journal of Environmental Science and Technology, 2015. 12(2): p. 617-632. 